\title{
When Logic Meets Politics: Testimony, Distrust, and Rhetorical Disadvantage
}

\author{
TRUDY GOVIER
}

Key Words: Feminism; epistemology; testimony; credibility; trust; distrust; belief; marginalization; rhetoric.

\begin{abstract}
The contested testimony in the HillThomas case is an illuminating test case for universalistic theories about the reliability of testimony. There is no reasonable alternative to universalistic standards of epistemic appraisal. And yet the charge by feminists and others that such criteria can be applied selectively and used to discredit and silence people is shown to be accurate. The road to a solution is to offer guidelines for the interpretation and application of these norms.
\end{abstract}

Feminist theorists allege that standards couched in universalistic terms are often implicitly racist and sexist. Universalistic theories, they claim, hide differences that relevantly affect how people have suffered in the past, are treated, and should be treated. The claim is usually made against political and moral theory, but can be made for epistemology and logic-as has been argued by Lorraine Code and Andrea Nye among others. ${ }^{1}$

Law professor Anita Hill's allegations of sexual harassment against U.S. Supreme Court nominee Clarence Thomas provide a compelling contemporary example of contested testimony. The case is one in which we can consider how well universalistic models work, in the epistemic and logical evaluation of testimonial claims made by someone in a marginalized group. The testimony offered was startling or troubling in its implications for those deciding whether to accept it. ${ }^{2}$

To introduce my exploration of norms for evaluating testimonial claims, I briefly explain what 1 mean by testimonial claims, credibility, and trust.
Testimonial claims are those which describe or purport to describe a particular person's observations, experience and related memories. It is useful to distinguish between narrowly and broadly testimonial claims. Narrowly testimonial claims are those made by the person whose experience and memory are at issue. (Example: "He fondled my breasts and asked me to come after work and finish the project with him at his apartment," where the person making the claim is the person who underwent this experience.) Broadly testimonial claims are those in which someone is recounting what he or she has heard or read stated by others. (Example: "He told me the white person would not give him a job because he was a native," where the person making the claim is recounting something told to him by another.) Of course, people tell us many things which are neither broadly nor narrowly testimonial-claims of synthesis, analysis, interpretation, or personal authority. ${ }^{3}$

Testimonial claims are especially important for a variety of reasons. Human knowledge is utterly dependent upon our acceptance, much of the time, of what other people tell us. Only thus can we learn language and pass on knowledge from generation to generation; only thus have we access to times, places, and cultures we do not and cannot experience ourselves. As persons who would tell others what we have observed, experienced, and remembered, we want and need to be listened to and have our testimonial claims believed. In consistency, then, we have reason to give credence to others. Narrowly testimonial 
claims have a special role here; to dismiss as generally unworthy or incredible another's claims as to personal experience and memories is, in effect, to dismiss that person as a person, to deny respect for his or her consciousness and perspective on the world. ${ }^{4}$

In a normative sense, a person's credibility may be defined as his or her worthiness to be believed. Normative credibility depends on a person's sincerity, honesty, and reliability. A person is normatively credible if and only if he or she is honest and is in an appropriate position to be a believable asserter of the sort of claim made. In the case of narrowly testimonial claims, what is at issue epistemically is the capacity for accurate observation, interpretation, memory, and description of one's own experience; at issue ethically are sincerity and truthfulness. ${ }^{5}$ In contrast to normative credibility there is rhetorical credibility, the extent to which one is regarded as believable, and is believed, by others. People who are white and male, who dress well, look professional, appear middle class or upper middle class, speak without an accent in a deep or low-toned voice, and seem unemotional, rational and articulate, tend in many contexts to have more rhetorical credibility than others. Often those who lack such qualities are, in effect, rhetorically disadvantaged. ${ }^{6}$

To trust another person is to regard him or her as one of integrity and character, one likely to act in benevolent and positive ways, not in harmful ways. The trustworthiness of a person depends on both motivation and competence. Often trust is directed toward action: to trust is to have confident expectations about what others, to whom we are vulnerable, are likely to do. In the context of testimony, trust is more restricted in scope: to trust a person is to believe what that person says, to take him or her to be making a statement because he or she honestly thinks it is true and wants to communicate belief for that reason, not in order to mislead or manipulate us. Trust here amounts to a willingness to take the other person at his or her word.

As various authors and philosophers have pointed out, our reliance upon testimony as a source of knowledge and belief is great, and accepting testimonial claims presupposes trusting those who make them. ${ }^{7}$ There are contexts in which, without critical reflection, we simply have to believe people and accept what they tell us; in such contexts, we acquire knowledge or beliefs from others because we trust them implicitly and completely. However, in a wide range of other cases, we reflectively evaluate testimonial claims. In such cases to accept the claim still entails trusting the person who makes it insofar as we rely, after our own reflective appraisal, on what that person says.

Here is a plausible model for the evaluation of testimonial claims. The model does not pretend to handle cases in which several people make conflicting testimonial claims, and it handles one claim at a time. Despite being in these respects oversimplified it raises some of the important questions we need to address in appraising the reliability of testimony. This model is "universalistic" in that it makes no reference to such features as gender, race, culture, age, voice, accent, appearance, or social role. It reads as though these aspects of persons will have no bearing on the acceptability of their testimonial claims.

\section{Universalistic Reflective Model}

1. A says " $p "$.

2. In saying "p" A asserts that $p$.

3. $A$ is sincere and truthful in his or her assertion that $\mathrm{p}$.

So,

4. A believes that $\mathrm{p}$.

5. $\mathrm{A}$ is (in the normative sense) competent and reliable with regard to such matters as $p$.

Thus,

6. There is good reason to believe that p.

7. There is no compelling reason or evidence against $\mathrm{p}$.

Therefore, probably,

8. p. 
If any person, B, follows the argument and accepts its premises, $B$ is provided with reasons for believing that $p$. There are several grounds for B's believing that $\mathrm{p}$, one of which is that $\mathrm{A}$ has asserted $\mathrm{p}$. Insofar as B is convinced by this argument, B believes p; $\mathrm{B}$ does not simply believe $\mathrm{A}$. (What believing $\mathrm{A}$ as a person amounts to is a nice question; at the very least it involves omitting step 7.)

Note that the Universalistic Reflective Model is just the sort of model that feminist theorists have complained about: it is couched in universal, apparently neutral, language. B and A can be any persons; $\mathrm{p}$ can be any claim. The context in which $A$ says " $p$ " to B can be any context. This model, then, is officially neutral as to persons, content of claim, audience, and context. Whether an authoritative-looking neuro-surgeon tells a colleague he has just found a tumor in the brain of a gorilla, or a vulnerable upset child testifies to a judge in court that her father regularly whips her with a belt, the formal representation is the same: A says "p" to B.

This model requires careful critical evaluation of testimonial claims, which proceeds in stages. From (1), (2), and (3) to (4) is an Argument to Asserted Belief; from (4) and (5) to (6) an Argument to Transmissible Good Reasons; from (6) and (7) an Argument for Acceptance.

$$
\begin{aligned}
& \text { Argument to }+(2)+3 \\
& \text { Asserted Belief } \\
& \begin{array}{l}
\text { Argument to }+(5) \\
\text { Transmissable } \\
\text { Good Reasons } \\
\begin{array}{c}
\text { Argument for } \\
\text { Acceptance }
\end{array}
\end{array}
\end{aligned}
$$

It is important to note that even this systematic reflective evaluation does not eliminate a need for trust in A. Key premises in the first and second stages of the argument, (3) and (5), are about A's truthfulness, sincerity, competence, and reliability. If $\mathrm{B}$ ac- cepts $p$ on the basis of A's testimony, that presupposes B's trusting $\mathrm{A}$, because the fact that $A$ believes $p$ is an indispensable part of B's reason for accepting it. ${ }^{8}$

As portrayed in the press, the reasoning about Hill's testimony as to sexual harassment and Thomas's denial was unimpressive, to put it mildly. The fact that Thomas's nomination was ratified, despite Hill's testimony to the effect that he had sexually harassed her by describing to her pornographic films of women having sex with animals and bragging about the size of his penis, suggests that a majority of U.S. senators disbelieved Hill. ${ }^{9}$ Polls indicated that a majority of Americans, women as well as men, found Clarence Thomas more believable than Anita Hill. The explanation-or justification-was not clear. If people had reasoned 'better' would the results have been different? One would like to think so; however there is reason for pessimism, as subsequent deliberations show.

While sensible and reasonable from a logical point of view, the Reflective Universalistic Model gives ample scope for the operation of facile stereotyping, prejudice, resulting in marginalization. It can be used in such a way as to provide a 'rational' 'critical' basis for rejecting claims that run contrary to our favored pictures of the social world. Unfortunately, the model provides considerable opportunity to dismiss unwelcome testimony, on perfectly 'reasonable' grounds. In saying this I do not mean to condone the cavalier dismissal of testimony from those against whom we are for some reason prejudiced, but rather to say that a person, B, could comply with the model as stated, using it to evaluate a testimonial claim, and nevertheless come to reject A's claim on the basis of erroneous stereotyping and prejudice. What appear as universal canons of reasonableness can, in practice, work selectively and prejudicially, as feminist critics have alleged.

It is a salutary exercise to follow through the various premises of the model 
and see how this happens. Begin with premise (2) in the Argument to Asserted Belief. In this premise we moving from hearing or reading what $A$ says in the sense of utterance to what A asserts. Supposedly $A$ is just anybody and " $p$ " is just any putatively assertive utterance. But when B judges whether $A$ is asserting that $p$ when A says " $p$ ", there are particular features of $A$ and the uttering of " $p$ " that B will take into account. What is the style and tone of the utterance? Does A speak in a declarative style? Does she understand and seriously mean what she is saying? Is she joking, teasing, speaking non-literally, trying to get attention, just venting her emotions? Is she deluded, imagining things?

Such factors are often properly taken into account. Suppose B is a mother listening to $\mathrm{A}$, her seven year old son, excitedly telling her about his new teacher. "She has neon colored braces", he says. B thinks, "That can't be true; he's either just kidding or trying to get my attention. Neon is such a fad with kids right now." (A was kidding and $B$ was right: the teacher had braces, but they were ordinary metal ones.) Or suppose that B is a white middle class citizen, concerned but confused about native issues, listening to $\mathrm{A}$, who is a native leader being interviewed on television. A says to the television interviewer that he was sexually abused in native residential schools in the fifties and adds "those who were abused have become abusers". He has a soft diffident voice and does not always look straight at the camera. B has often seen $A$ interviewed so frequently on television before that she feels that she knows him personally. But his previous comments were about land claims and the violent confrontation over land at Oka, not this. Is he confessing? Telling the audience he has abused women and children? Hinting at a general problem? B doesn't know how to take it. 10

People may be interpreted as speaking unseriously, jokingly, indirectly, allusively, metaphorically, or ironically-anything but making a straightforward assertion of something they believe to be true because they believe it to be true-on the basis of their personal mannerisms and speaking style. But these features vary with age, social class, race, and gender. Those of a 'nonstandard' (not adult, white, male, Anglo-Saxon) background may be taken as not speaking seriously, not intending to make assertions - despite the fact that they are making assertions, in the only way they know how."

Here's an example based on a real case. $A$ is a woman in her early seventies who suffered from a lingering flu that left her exhausted. When $\mathrm{A}$ is well, she works as a volunteer for several action groups, hikes and skis, and attends many lectures and films. A consults a doctor, B. (B, in case it's relevant, is female.) $B$ refuses to accept A's claim that she has been ill; in fact, she hardly understands $A$ even to be asserting that she is ill. B advises $A$ that the solution to her problem is to stop watching so much television and become more active. $\mathrm{B}$ has simply categorized $\mathrm{A}$ as an old person"these old people just sit around the house all the time" - and as a result fails to understand what $A$ says as a statement that she is ill. Instead, B takes A's comments as a bored and predictable grumble, signifying nothing.

People may be assumed to be deluded or imagining things simply because they are categorized as "juvenile", 'immature", 'mere women', 'mere men', 'one of them', one of 'those people'-the possibilities are endless. Perhaps when she said "he showed me pictures" Anita Hill was not really asserting that Clarence Thomas showed her pictures? Maybe she was fantasizing? Or deluded?

People who are immature, irrational, or unserious may really not mean what they seem to be saying. They may utter " $p$ " in a style somewhat appropriate to making an assertion, and yet not assert that $p$. That is, those who really are immature, irrational, or unserious. But all this raises obvious 
problems. Such people often have important stories to tell. Some of these storieseven the implausible ones-turn out to be true. Here's an anecdote that illustrates the point. When my son was three, he told me the children at his daycare drank tea. I didn't believe him, didn't take his words as a serious assertion, thinking there must be some confusion (he didn't know what tea was, or confused play tea parties with really drinking tea). He was so young that such an interpretation seemed sensible. I got this one wrong - as I discovered when I arrived one day to pick him up and found that, indeed, camomile tea was being served to the children.

Standards of rationality, seriousness, and maturity incorporate norms that are not neutral as regards age, gender, race, class, culture, and style. Who is likely to seem immature, irrational, or unserious? Children, who really are immature, but nevertheless sometimes tell true and important stories about what happened to them. Old people, who may be suspected of losing their memory, being confused, being senile. Women-especially those who are small, timid in manner, have high voices, speak with qualifications and tonalities of uncertainty, dress in a feminine style connoting prettiness, a desire to please, non-seriousness . . . The poor, who need assistance and advice from others. Patients and others who are in positions of dependency. Minority peoples- those of another race, culture, or linguistic backgroundespecially those who seem shy or illat-ease in a situation of vulnerability to those in power, who may fail to make eye contact as a sign of respect, who observe different conventions about loudriess, body space, body language, emotionality in speech, who may speak awkwardly or with accents. They can't be taken 'seriously', not 'literally'. They may not mean what they say. They are, perhaps, too caught up in their own feelings and culture to 'accurately' and 'rationally' articulate what they have to say. All such rhetorically disadvantaged people are too easily dismissable - and dismissed-as incapable of making serious, reasonably articulated assertions.

Move on to premise (3). To accept A's claim as testimony, $B$ has to believe that $A$ is not only asserting it. but sincerely and truthfully asserting it. In this area too, there are many opportunities for prejudice and stereotype to operate. B may have no special knowledge of $\mathrm{A}$ as an individual and detect nothing conspicuously sincere or conspicuously insincere when A asserts $p$. Despite the absence of directly relevant information, B has to make some kind of judgment about how truthful and reliable A is. So B categorizes A; B classifies A as a member of some group about which $B$ does have some (apparently) relevant knowledge or beliefs, and B brings his or her knowledge of that group to bear on $\mathrm{A}$ as an individual. ${ }^{12}$ ( $\mathrm{B}$ thinks: ' $\mathrm{A}$ is an $\mathrm{X}$, and $\mathrm{X}$ 's are generally ..., so $\mathrm{A}$ is probably ...) $\mathrm{B}$, like any human being, is in possession of some categories he or she assumes and considers to be relevant to the case. In applying such categories, B can easily lapse into stereotyping, transferring distrust from groups to an individual.

Suppose B is a judge: A stands before $B$ to assert that if he is forced to leave Canada and return to his own country he will surely be killed by the police; they have, he says, tortured him before, and killed his brother. Let's say B does not know A, don't know much about A's country, and can't tell whether $\mathrm{A}$ is speaking truthfully or not. B tries to locate or "place' $A$, to understand what sort of person $A$ is and what $A$ is trying to do. And $B$ comes up with this: $A$ is a south-east Asian claiming refugee status; $A$ has been an illegal worker; and A is Tamil. Who are Tamils? Well, what does B know about them? They're a rebel group in Sri Lanka, one which (B seems to recall) has often had recourse to violence. A Tamil is "one of those people who lied so grotesquely in the past," B may think to himself, recalling the 
notorious boatload of Tamil refugees found a few years back, drifting off Newfoundland, claiming to have come from India and found later to have set off from Germany..$^{13} \mathrm{~B}$ finds at last 'relevant' evidence about A's honesty ('A is Tamil; Tamils have lied; A may be lying') and decides, on the basis of that evidence, not to accept A's story.

In any context in which one is dealing with a person not known as an individual, there are ample stereotypical categorizations available. In fact, it is safe to say that any person can be made out to be the member of some group which can be plausibly seen as unreliable, untruthful, insincere due to vested interests, or in some other way lacking in credibility. ${ }^{14}$ Those who do not seem mature, rational and serious in what they are saying - or who can, on the basis of personal style or stereotype, be deemed untruthful-fail to pass muster and are disqualified even from truthfully asserting testimonial claims-still less having their testimony respectfully heard and accepted.

The same sorts of issues arise againand with a vengeance-in the Argument to Transmissible Good Reason. Granting that $A$ has asserted that $p$ and believes that $p$, A's belief that $p$ can give $B$ a good reason to believe that $p$ only if $B$ assumes that $A$ is competent and reliable on matters such as p. Relevant to B's decision that A is in fact reliable and competent are B's knowledge as to A's qualifications and past accuracy on similar matters. Irrelevant to it are A's gender, race, age, appearance, and cultural style. Premise (5) can be supported-or rebutted-by relevant evidence about the person at issue, but it can alsoapparently-be supported or rebutted on the basis of stereotyping and prejudice. B can too easily assume that no one of suchand-such a type could possibly be a reliable and competent judge of the matter in question. (She is 'too young, too old, too pretty, too ugly, too deferential, too argumentative.' $\mathrm{He}$ is 'too young, too old, too loud, too poor, too unqualified, too aggressive, too low class.' And so on and so forth.) A may assert a proposition and believe it, but if $B$ does not regard $A$ as a reliable competent judge on the matter, $A$ 's belief provides no reason for $B$ to believe. That $\mathrm{A}$ asserts $\mathrm{p}$ may be of interest to $\mathrm{B}$, but won't in such a case provide B with any reason to think that $p$ is true or probable. ${ }^{15}$

Further problems arise at the next stage, in the Argument to Acceptance. By the time $B$ reaches this stage of the argument, B has granted A a lot. B has interpreted what was said by $\mathrm{A}$ as a straightforward assertion, and has granted that $\mathrm{A}$ is reliable and competent: thus $B$ acknowledges that $A$ believes $p$ and that A's believing $p$ gives $B$ some reason to believe $p$. In effect, $B$ has granted A normative credibility. If there were temptations to ignore or discount what A said, due to epistemically irrelevant assumptions about gender, class, race, age, or personal style, B has overcome them.

But opportunities for partiality are not over. In the Argument to Acceptance, B brings his or her other beliefs and knowledge to bear on $\mathrm{p}$. That $\mathrm{A}$, a credible and reliable person, has sincerely asserted that $p$ gives $B$ good reason to accept that $p$, and $B$ will accept $p$ on the basis of A's sayso, provided that $B$ does not have independent reasons to think that $p$ is false. This condition is surely sensible and reasonable and it is ostensibly neutral. However it is apt to be selective and non-neutral in its impact. To the extent that $\mathrm{A}$ is a person different from $B$ in experience, social standing, gender and so on, B is likely to have established beliefs and preconceptions different from those of A. Ironically the very features that make A's testimony necessary, intellectually interesting, and important to $B$ may also serve to render it unbelievable.

Consider an example in which B is a middle-aged woman and $A$ is a young man. Suppose now that A tells B that much of boys' playground behavior when he was growing up was aimed at establishing a clear pecking order of domination based 
mainly on physical prowess. And suppose that $\mathbf{B}$, who went to an all-girls school decades before, has only one son, a rather docile boy, and has led a rather sheltered life, finds in her experience nothing to correspond with this phenomenon. $B$ finds the story hard to believe, hard to credit, perhaps even impossible to believe. ${ }^{16}$ She has not experienced boys and men as being all that concerned with pecking order. Yet, to $\mathrm{B}$, A seems truthful, reliable, sensible, and $\mathrm{A}$ is telling $\mathrm{B}$ what playground encounters were like for him. To accept what $\mathrm{A}$ has to say, B may have to revise some of her own beliefs. ${ }^{17}$ And one can think of many similar cases.

Insofar as another person's testimonial claim is about aspects of life to which we have limited access, the likelihood of its content being contrary to our established beliefs is greater. Hence the likelihood of our accepting testimonial claims from those differing from ourselves in gender, culture, race, age, class, and so on is in general less than the likelihood of our accepting such claims from others who are similar to us in background.

From all of this I sadly conclude that even if an informal logician or philosopher had been given the opportunity to lecture the entire U.S. Senate, thereby convincing all of them to adopt Rules for the Universalistic Reflective Evaluation of Testimonial Claims, appropriately unbiased and fair attitudes leading to an epistemically responsible evaluation of the Thomas-Hill testimony would by no means have been guaranteed. There is ample scope, within this model, for the operation of prejudice, stereotyping, and closed-mindedness; ample basis for not believing - or not even listening to- the other person who is truly other. ${ }^{18}$ These considerations tend to corroborate the feminist allegation that, in practice, purportedly universalistic models are all too often partial and selective.

I think this is an important problem, a problem not only within logic and epistemology, but for politics and ethics. A ten- dency to systematically dismiss the testimony of rhetorically disadvantaged persons is harmful both to those persons and to those who deprive them of a voice. Those dismissed lose dignity and power; those who will not hear or will not believe lose potentially valuable information and insight. To be viewed as someone less than serious, mature, and capable of articulating one's own personal experience is, to a significant degree, to be rejected as a person. The person whose testimony is systematically dismissed or disbelieved is not granted proper respect: he or she is deemed to be one who cannot reliably experience and describe the world, or whose experiences are of no significance to other people. Such treatment is likely to result in lack of self-respect, severely affecting one's competence, relationships, and actions. ${ }^{19}$ It results as well in a lack of social power; the person (A) not heard or not believed has little redress against abuse or injustice, little chance that his or her side of the social story will have an impact on social decisions and policies. We (B) who do not listen or cannot believe deprive ourselves of relevant knowledge and understanding, of information and insight we cannot obtain save by listening to those who have 'been there'. In effect, we restrict admission to the community of knowledge, ${ }^{20}$ distorting our understanding of the world and cutting ourselves off from the possibility of improving it. We preserve for ourselves a distorted picture of the social world, thereby losing opportunities to improve social practices and institutions.

Thus the problem of rejecting testimony on the basis of gender, race, class, or other prejudice is a serious one. How can we address this problem? Three ultimately unsatisfactory approaches suggest themselves: I conclude by proposing a fourth approach.

One might respond that there is no need to respond because the 'problem' is an inevitable aspect of social life: that it is natural for some people to have more 
rhetorical credibility than others, that inevitably some groups are going to be understood and categorized in unfavorable ways and of course these unfavorable descriptions are going to be applied to particular people located within the groups. ${ }^{21}$ These things are inevitable; there is a kind of realpolitik of credibility.

But here as elsewhere realpolitik merely re-describes a problem; it does not offer a solution. Not only is the realpolitik approach ethically and politically objectionable in its complacency about disrespect and injustice, it is descriptively oversimple in omitting any role for human reflection, normative evaluation, and initiated change. ${ }^{22}$ The social world does not simply churn along inevitably, independently of the way human agents make it work. Human actions, choices, and attitudes construct and constitute the social world. And these can be changed.

Another possible response to the problem of rhetorical marginalization is to cultivate 'standard' rhetorical credibility in those groups likely to be discredited. Advise 'these people' to dress in the 'right' way, lower their voices, get rid of their accents, adopt waspish or mainstream body language, lose weight, avoid emotionality of language, and so on and so forth. "Why can't a woman be more like a man?", asked Henry Higgins in My Fair Lady -after he had already corrected Eliza's speech so that she would have the right accent for rhetorical credibility!)

Insofar as needed changes are impossible, we might seek advocates to speak on behalf of the rhetorically disadvantaged. Children, for instance, can be given their own lawyers in abuse or custody cases; older people who might be stereotyped as senile could be represented by others. The rhetorically disadvantaged will then (at least indirectly) be heard, because they or their advocates, will acquire an accepted rhetorical style. This sort of response may be practically advisable in some formal contexts-as, for instance, when someone appears in court. However it is not practical as a completely general response and is, in addition, ethically and politically undesirable as too assimilationist, depriving the 'rhetorically disadvantaged' of an authentic voice. It assumes permanency of the prejudice and distrust that create rhetorical disadvantage and caters to them, placing the onus for correction on people already disproportionately burdened. Also, such an approach will be rejected by those among the marginalized who do not want to assimilate to the dominant culture, finding their identity and taking pride in another culture.

Another suggestion would be to alter our social practices so as to give extra credibility to the rhetorically disadvantaged. In recognition of the likelihood that we too easily fail to genuinely listen to these 'others' and prejudicially deny them respect, we should effectively forego all criticism of claims made by these 'minorities'. Some observers allege that such a strategy is already operative as an aspect of so-called political correctness. Lethbridge sociologist Reginald Bibby alleged that the failure of the Meech Lake Accord, stalled in the Manitoba Legislature by the single dissenting voice of native member Elijah Harper, was possible only due to the general belief that no fair-minded person would "bad-mouth a native." 23

The response of Clarence Thomas to Anita Hill's allegations is noteworthy in this context. Thomas sought shelter under the mantle of blackness, accusing those who disbelieved him of being racist.

Fashionable or not, a reverse discrimination for credibility, wherein we refuse to critically evaluate claims made by the hitherto rhetorically disadvantaged people, would be logically and epistemically irresponsible and politically dangerous-due to the likelihood of backlash and effective disempowerment of the hitherto rhetorically advantaged. In addition, it is ultimately contradictory in its implications, as illustrated in the Hill-Thomas case. One cannot 
simply accept the story of anyone who is rhetorically disadvantaged: too many people are in too many different ways rhetorically disadvantaged, and their stories conflict. In the Hill-Thomas case, one had to choose between disbelieving a black man and disbelieving a black woman. Framing the issue in this way contributes neither to accurate thought and reflective understanding nor to a social life based on respect for persons.

For a more satisfactory approach, let us return to the Universalistic Reflective Model to see what more can be said. In that model, the premises that provide opportunities for prejudice, rationalization, and closed-mindedness are (2), (3), (5), and (7). We might think of these premises as each requiring support in subarguments: thus if $B$ is to regard $A$ as speaking assertively when he or she utters a declarative sentence, $B$ requires specific evidence as to context, tone, etc., which will show that $A$ is making an assertion; if $B$ is to deem $A$ truthful and sincere, $B$ needs relevant evidence for that; similarly for competence and reliability. Yet this interpretation, while natural, is not quite right. It is denied by various authors who have written on testimony. The prevailing view is that people are deemed trustworthy as to their own experience (that is, with regard to narrowly testimonial claims) unless there is some clear evidence to the contrary. This is to say, in effect, that the onus is in favor of normative credibility as required in premises (2), (3), and (5). B should grant, or assume, that $\mathrm{A}$, who seems to be telling $\mathrm{B}$ his or her story, is indeed truthfully doing so and is sufficiently competent to get that story right. These premises are granted, other things being equal-granted unless there is clear evidence to the contrary.

But of course this opens up all the questions again. What is 'clear evidence to the contrary'? Insofar as B may tend to systematically discredit women, the aged, blacks, natives, children, and others, B thinks he or she has 'clear evidence' to justify doing so. We need a restriction on what can count as 'clear evidence'. This restriction has to do with categorization. No evidence against premises (2), (3), or (5) is to be taken into account if it is evidence about groups within which A may be located and not evidence about $A$ as an individual. For instance, if $\mathrm{A}$ is seventy years old, the proposition that 'many old people are confused' cannot be allowed to count against (5) (asserting A's competence and reliability), for it is $A$ as an individual and not 'many old people' whose claim is at issue. And so for other categories. Evidence must be about A himself or herself and must not bear on $A$ indirectly merely through A's being labelled in a way that facilitates group-based rhetorical discreditation., ${ }^{24}$

As to the final stage of the argument, with regard to premise (7), we must reflect further about what can count against compelling evidence against another person's narrowly testimonial claim. One might attempt to solve the problem by saying that, in the nature of the case, no one can have compelling reason to disbelieve another's narrowly testimonial claim: what we know and believe cannot set boundaries limiting what another can experience. However, this solution fails because we often have universal beliefs, or beliefs as to what is and is not possible. For example, someone might believe that it is in some strong sense natural for parents to care for their children and that all human societies will accommodate this instinct. Yet in his book The Mountain People anthropologist Colin Turnbull tells of (testifies to) his experiences living among the $\mathrm{lk}$, a desperate mountain people in Africa. Turnbull reports that among the $\mathrm{Ik}$ children were turned out of the parents' hut at three to forage for themselves. Many starved to death and their parents found this an occasion for no emotion save, possibly, amusement. ${ }^{25}$ Turnbull's claim is narrowly testimonial: he is telling readers what he observed during his two year stay among 
the Ik. Even when regarded as a sequence of narrowly testimonial claims, this story runs contrary to some cherished beliefs about human nature. What many of us believe to be impossible in a human society, Turnbull claims to have observed.

Thus some narrowly testimonial claims do have revisionary implications. Such claims are the most likely to be rejected at the stage of premise (7). And yet they are the most likely to generate new insights and make valuable additions to our understanding of the world. In response to this problem, we should make every effort not to be dogmatic, to be open to what other people are telling us, not to close our minds because we think we 'know' something that shows that what they have to say just could not be true.

Given that we appear to have knowledge or confirmed beliefs constituting compelling evidence against $p$, we can articulate those beliefs and examine them critically, making every effort to examine their status. If we decide that they are, indeed, reasonably well-confirmed, we can then reflect further on the extent to which they are compatible with what we are being told when $A$ asserts that $p$. What exactly are the implications of what we 'know' for $p$, and what exactly are the implications of $p$ for what we 'know'? By qualifying universal generalizations, by accepting $\mathrm{p}$ as an anomaly, by making corrections (for example amending ' $x$ is impossible for human beings' to ' $x$ is possible but probably rare among human beings'), by tentatively accepting $p$ as worthy of further investigation ... we can avoid the risk of simply closing ourselves off to what those of genuinely different character and experience may encounter.

In conclusion, I suggest that we can continue to state and explain norms and criteria for epistemic appraisal in universalistic terms--while granting there are important truths in the feminist allegation that such norms can work selectively. In practice, it is all too easy to interpret and apply criteria in such a way as to marginalize and discredit those who are rhetorically disadvantaged. And yet giving up on universalistic norms is no solution-if, indeed, it is feasible at all. The solution, I suggest, is to be found in offering further guidance for the interpretation and application of these norms. Such guidance is intended to protect us from those political-epistemic temptations that may prevent us from hearing and believing what others have to say.

\section{Notes}

Lorraine Code, What Can She Know? Feminist Theory and the Construction of Knowledge. Ithaca and London: Cornell University Press, 1991. Chapters One and Six.

2 What is meant by a model for evaluating testimony will become clearer later, but two qualifications merit special attention. The model applies to testimony of one person, not to the more complex case where two people offer conflicting testimony and one must decide which one, if either, to believe. The model treats testimonial claims one at a time, whereas often a person's story includes many claims together and an important aspect of its credibility concems their joint consistency and plausibility. These limitations do not undermine the arguments developed here. Problems with this relatively simple model will be multiplied, not solved, if one is working with models handling several persons and multiple claims.

3 Not intended as an exhaustive list. Of course many subtle distinctions could profitably be introduced here, but this is not the subject of the present paper.

4 A number of writers on testimony have mentioned the connection between a preparedness to believe what someone tells you and a relationship of respect. See, for instance, G.E.M. Anscombe, "What is it to Believe Someone?", in C.F. Delaney (ed.) Rationality and Religious Belief (Notre Dame: University of Notre 
Dame Press 1979); Keith Lehrer, "Social Information" Monist 60 (1977), pp. 473-487, Sidney Shoemaker, Self-Knowledge and SelfIdentity (Ithaca: Cornell University Press, 1963), pp. 225-232; and H.H. Price, Belief (London: George Allen and Unwin, 1969). Price, for instance, says "Am I treating my neighbour as an end in himself, in the way I wish him to treat me, if I very carefully examine his credentials before believing anything he says to me? Surely every person, just because he is a person, has at least a prima facie case to be believed when he makes a statement." (pp. 114-115) Shoemaker sees believing what people tell us about their observations and memories as a necessary aspect of our form of life in which other human beings are regarded as persons.

5 For concepts of normative credibility, see Robert Ennis, "The Believability of People", The Educational Forum March 1974, p. 347; Alan Brinton, "A Rhetorical View of the Ad Hominem", Australasian Journal of Philosophy 63 no. 1, pp. 50-63; and Trudy Govier, Problems in Argument Analysis and Evaluation (Dordrecht, Nthlds: Foris, 1987), Chapter Thirteen, and A Practical Study of Argument Third Edition (Belmont, CA: Wadsworth, 1992), Chapter Five.

Discussions of credibility among speech theorists and social psychologists strike me as not attending to the distinction between logicoepistemic features (which I would deem normative) and persuasive ones (here called rhetorical). See, for example, Kim Giffin, "The Contribution of Studies of Source Credibility to a Theory of Interpersonal Trust in the Communication Process", Psychological Bulletin 1957 Vol. 65 no. 2, pp. 104-120. After reviewing many studies, Giffin lists five characteristics making for source credibility; these are (1) expertness (2) reliability (3) intentions (4) dynamism and (5) personal attractiveness. See also W. Barnett Pearce, "Trust in Interpersonal Communication", Speech Monographs Vol. 41 , no. 3 (August 1974), pp. 236-244.

7 Among those who have stressed the absolutely basic role of testimony in human knowledge are Wittgenstein in On Certainty (Oxford: Basil Blackwell, 1959); Lorraine Code, in Epistemic Responsibility (Hanover and London: University Press of New England, 1987), especially Chapter Seven; H.H. Price Belief; Sydney Shoemaker, Self-Knowledge and
Self-Identity; Michael Welbourne, "The Community of Knowledge", Philosophical Quarterly 31 (1981), pp. 302-314; John Hardwig, "Epistemic Dependence", in Journal of Philosophy LXXXII no. 7 (July 1985), pp. 335 -349; and C.A.J. Coady, "Testimony and Observation", American Philosophical Quarterly Vol. 10, no. 2, pp. I49-155.

8 The connection between testimony and trust has also been stressed by other authors, most notably Hardwig, who ends his article by saying that rationality depends on trust.

9 It is also possible, of course, that the senators believed Hill but deemed such behavior on the part of Thomas to be normal or acceptable, or to indicate at worst only minor character flaws -flaws irrelevant to his suitability for a Supreme Court position. This possibility, in some ways more disturbing than the hypothesis that the senators disbelieved Hill, may be true, and would locate the fundamental problem of the case elsewhere than in the belief or disbelief in testimony. My point here is not to offer a definitive analysis of the Thomas-Hill case but to use it as a stimulus for more general reflection.

10 Based on a real example. As I recall, the speaker told of abuse in residential schools and then said, "Those who suffered abuse have become abusers". This way of putting the matter leaves open the possibility that he was asserting "Many of those who were abused have become abusers" or "Most of those who were abused have become abusers", and not including himself. On the other hand, he might have meant "all of those". The interviewer was too tactful to insist on clarifying the matter.

11 The issue of whether $p$ is asserted, and its significance for the logic of testimony, is interestingly explored by David Cooper in "Assertion, Phenomenology, and Essence", Aristotelian Society Supplementary Volume 1987, pp. 85-106.

12 The logic and ethics of treating people via the application of categories is a fertile topic for future investigation.

13 In the summer of 1986 a group of Tamil refugees rescued from a shaky vessel were brought to Newfoundland; they claimed to have drifted into the North Atlantic directly from southern India but were soon discovered to have lived in Germany and come from Europe. One group member appeared on Canadian national television, looked straight into the camera, and 
lied blatantly, in clear English, about their circumstances.

14 People can be categorized in many different ways and are members of many different groups, some of which are and some of which are not 'rhetorically advantaged' in the sense described here. A person may, for instance, be male, slim, around 35, good looking, low voiced, yet black; or may be well-spoken, well-educated, apparently moderate, white. yet female and overweight. All of us were once children; most will some day be old. No one is safe from irrelevant discreditation-a point which can provide additional reason for not engaging in it, should such reason be needed. In some circles the white waspish middle class middle-aged males who are supposed to be paradigmatically credible are now a negatively stereotyped group. I don't consider this to be progress: one instance of negative stereotyping is no more acceptable-logically, ethically, or politically - than another.

15 To refer back to the argumentative structure, premise (5) is not granted, so we do not derive (6) from (4) and (5).

16 To say that one finds something thard to believe' is typically to say that it is contrary to what one has experienced or thinks one knows. To say that something is "impossible to believe' is to say that one finds it difficult to believe, not quite to say that it is scientifically or metaphysically or logically impossible. The colloquial use of these and related expressions strikes me as meriting analysis.

17 There are of course a variety of ways this claim could be made compatible with one's beliefs.

18 The expression 'truly other' refers to those others who differ from us as to culture, gender, race, or other features that make their experience, values, and interpretations different, or likely to be different, from our own.

19 Intersections between attitudes to oneself, attitudes to others, and responses from others are discussed by Mark Snyder in "When Belief Creates Reality", in Advances in Experimental Social Psychology 18, pp. 247-305.

20 Many empirical discussions of credibility seem to have this tone to them.

21 A fascinating counter-example to thetorical pessimism is presented by Michael Gismondi and Mary Richardson, in "Discourse and Power in Environmental Politics: Hearings on a Bleached Kraft Pulp Mill in Alberta Canada". Forthcoming in Our Generation.

22 One endorsing such a policy might reflect on its intended scope; it would, I think, make the most sense if taken to apply only to narrowly testimonial claims.

23 Reginald W. Bibby, Mosaic Madness: The Poverty and Potential of Life in Canada. Toronto: Stoddart Publishing Co., 1990), pp. 169-70.

24 Fine points of logic can surface here, as to the precise way we might make the distinction between describing someone as an individual and merely subsuming him or her under a category known to apply to a group. The technicalities of this distinction cannot be explored in the present context.

25 Colin Turnbull, The Mountain People. New York: Simon and Schuster, 1972.

\section{TRUDY GOVIER}

3207 CANMORE ROAD NW

CALGARY, ALBERTA T2M $4 J 8$ 